\title{
A Constituição de uma Sociologia Política no Brasil: Vínculos Entre o Pensamento Durkheimiano e a Interpretação de Oliveira Vianna sobre o Povo e as Instituições Políticas Brasileiras ${ }^{1}$
}

\author{
The Formation of a Political Sociology in Brazil: \\ the link between Durkheim's Theory and the \\ Oliveira Vianna's Interpretation about the People and \\ the Brazilian Political Institutions
}

\author{
Felipe Fontana \\ Doutorando em Ciência Política pela Universidade Federal de São Carlos (UFSCar) \\ buthjaum@hotmail.com \\ Thiago Pereira da Silva Mazucato \\ Mestrando em Ciência Política pela Universidade Federal de São Carlos (UFSCar) \\ t.mazuca@gmail.com
}

\begin{abstract}
Resumo: Oliveira Vianna, considerou determinadas características estruturais inerentes à formação de nosso povo e de nossas organizações/instituições. Populações Meridionais do Brasil (1922) constrói uma interpretação sobre o Brasil que, determinou o modo como o pensador encarou algumas saídas políticas necessárias ao país. Interessantemente, notamos como, para pensar a formação nacional e a construção de soluções mais adequadas ao Brasil, edificando, em seu pensamento, uma espécie de Sociologia Política, Vianna angariou uma gama significativa de ideias durkheimianas. Apresentaremos a interpretação vianniana sobre o Brasil; evidenciaremos como determinados conceitos durkheimianos são articulados pelo intelectual no momento em que ele constrói um diagnóstico e um prognóstico para a nação; e, por fim, exporemos como essas dimensões do pensamento do autor são relevantes para apreendermos a constituição de uma Sociologia Política Brasileira que se enraizou de diferentes maneiras em nosso Pensamento Social e Político.
\end{abstract}

Palavras-chave: Oliveira Vianna. Émile Durkheim. Formação do Brasil. Instituições Políticas Brasileiras. Sociologia Política no Brasil.

\begin{abstract}
Oliveira Vianna, considered certain structural characteristics of the formation of our people and our organizations and institutions. Populações Meridionais do Brasil (1922) builds to constitute an interpretation of Brazil that, determined the way that the thinker faced some political outputs necessary to the nation. Interestingly, we notice how, to think the Brazilian formation and the construction of more adequate solutions to Brazil, in his thought, a kind of political sociology, Vianna raised and used significant range of Durkheimian ideas. Thus, in this article, we present the Vianna's interpretation of Brazil; we going to show how certain Durkheim's concepts are articulated by the Brazilian intellectual when he builds a diagnosis and prognosis for the nation; finally, we will expose how these dimensions of the author's thought are relevant to us apprehend the constitution of a Brazilian Political Sociology that has created roots in different ways in our Social and Political Thought.
\end{abstract}

\footnotetext{
${ }^{1}$ Este trabalho é uma continuação, em termos de análises e de revisão, de um texto com igual título apresentado no IV EICS (Encontro Nacional de Ciências Sociais da Universidade Federal de Pelotas-RS, realizado em 18 de Novembro de 2014).
} 
Keywords: Oliveira Vianna. Émile Durkheim. Formation of Brazil. Brazilian Political Institutions. Political Sociology in Brazil.

Originais recebidos em: 20/06/2015

Aceito para publicação em: 09/08/2015

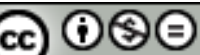

Cr No ND Este trabalho está licenciado sob uma Licença Creative Commons Atribuição-Uso NãoComercial-Vedada a criação de obras derivadas 3.0 Unported License. 


\section{Introdução}

Oliveira Vianna (1883-1951) foi um dos primeiros autores brasileiros que, para explicar de maneira profunda o Brasil, considerou as características estruturais inerentes à formação de nosso povo, de nossas organizações e de nossas instituições políticas. Populações Meridionais do Brasil (1922), por exemplo, é uma obra que tem a função de edificar uma interpretação orgânica sobre o Brasil. Esse importante diagnóstico acerca da realidade brasileira (aspectos sociais, culturais, econômicos e políticos que perduraram e nos caracterizam como povo e nação) determinou em muito o modo como o pensador encarava as nossas instituições e algumas das saídas políticas necessárias e mais adequadas para o Brasil. O interessante é notarmos como, para pensar a formação do Brasil e construir as soluções mais condizentes para a nação, edificando assim, em seu pensamento, uma espécie de Sociologia Política, Oliveira Vianna angaria uma gama significativa de conceitos, noções e ideias durkheimianas.

Nesse sentido, este artigo busca apresentar rapidamente a interpretação de Oliveira Vianna sobre o Brasil; evidenciar como determinadas ideias e conceitos de Émile Durkheim são articulados pelo intelectual brasileiro no momento em que ele constrói um diagnóstico e um prognóstico sobre a realidade brasileira; entender o vínculo dessa interpretação com as soluções políticas e institucionais propostas por Oliveira Vianna para desenvolver e modernizar o Brasil; e, por fim, analisar como essas dimensões do pensamento do autor são relevantes para apreendermos a constituição de uma Sociologia Política Brasileira que se enraizou em nosso Pensamento Social e Político, vinculando-se, dessa forma, de maneira discreta ou contundente, a diversos trabalhos, estudos e teorias.

Todavia, antes de adentrarmos especificamente na leitura de Oliveira Vianna sobre a formação do Brasil e os mecanismos necessários para se modernizar o país faremos, resumidamente e de modo a resguardar o objetivo deste trabalho, uma definição daquilo que entendemos por Sociologia Política. Segundo nossa visão, esse campo do conhecimento tem objetos de investigação muito próximos aos da Ciência Política, tais como: o Poder, o Estado, as Instituições Políticas e o Dever e a Função da Política. Contudo, o enfoque diferenciado dado à análise destes objetos liga-se, fundamentalmente, com a verificação e a compreensão das bases sociais da política; ou seja, quais os ditames e as peculiaridades sociais que interferem, modificam e influenciam a política. 
De modo geral, a Sociologia Política busca apreender as condições sociais que interferem na política e no poder, dessa forma, questões como as especificidades das elites políticas de uma sociedade; a particularidade dos grupos sociais fixados ou não no aparelho de Estado; as características e a importância dos grupos de pressão ou dos movimentos reivindicatórios; as consequências das ações coordenadas pelo Estado (a quem elas se destinam e em qual segmento social elas interferem); as peculiaridades das ideologias inerentes aos grupos sociais que atuam no Estado ou que detêm o poder; ou ainda, o modo como a sociedade está organizada e os impactos que um tipo específico de organização gera na política (HURTING, 1966, p. 74-107).

Essa visão mais canônica acerca do que é e do que representa a Sociologia Política ainda está, segundo nossa avaliação, muito presente nas reflexões contemporâneas daqueles que estão preocupados em discutir a relevância, a especificidade e a atualidade desse campo disciplinar. Na coletânea intitulada The Handbook of Political Sociology: States, Civil Societies, and Globalization (2005), especialmente em sua introdução denominada Political Sociology in the new Millennium, Thomas Janoski, Alexander Hicks e Mildred A. Schwartz nos evidenciam que apesar de complexas mudanças ${ }^{2}$ e, consequentemente, da constituição de novos desafios metodológicos e de pesquisa, os objetos de investigações e as contribuições científicas da Sociologia Política continuam indelevelmente atreladas à necessidade de dimensionar e analisar as bases sociais da política:

The very nature of the field that makes political sociology sociological comes from civil society in the broadest sense - everything about society that is either not the state or where the state has overlapped into other arenas. [...] The social bases of politics are located not at "Number 10 Downing Street," "the hallowed halls of Congress," "the White House," or "the new Bundestag building in Berlin." Rather they reside with citizens situated in groups like labor unions, women's groups, corporations, voluntary associations, and churches or other religious organizations. [...] Less directly, social bases are comprised of every citizen and sometimes even noncitizen residents. Collectively, we call all these nonstate entities civil society. They constitute the diverse interests, rationalities, emotions, and traditions that shape the state and its actions and are, in turn, shaped by it. The complexity of societal existence is reflected in deep-seated divisions, of which the most notable are

\footnotetext{
${ }^{2}$ Em termos de mudanças, observamos para os autores que há no meio científico: 1) a emergência de novas metodologias e técnicas de pesquisas ligadas às Ciências Sociais que, em grande medida, auxiliam na tarefa de compreender diferentes realidades e contextos sociais; 2) a consolidação de distintas teorias ou campos disciplinares - o Institucionalismo e a Rational Choice, por exemplo - com os quais é preciso estabelecer diálogos, seja para dinamizar os conhecimentos produzidos por meio de críticas e debates acerca de visões/interpretações unitárias e estanques da política, seja para complexificar o próprio saber advindo dos estudos vinculados à Sociologia Política. Já no ambiente social, os pesquisadores desta coletânea destacam o advento da globalização e as grandes transformações sofridas pelas sociedades nos últimos anos que, por sua vez, alteraram profundamente alguns esquemas, conceitos e categorias até então altamente explicativos na tarefa de compreender sociedades modernas, capitalistas e urbanas.
}

Em Debat: Rev. Dig., ISSNe 1980-3532, Florianópolis, n. 12, p. 110-135, jul-dez, 2014. 
social class, race, ethnicity, gender, and religion (JANOSKI, Thomas; HICKS, Alexander; SCHWARTZ, Mildred, 2005, p. 21-22).

No Brasil, também há um debate frutífero acerca da Sociologia Política. Renato Monseff Perissinotto, no artigo intitulado Política e sociedade: por uma volta à Sociologia Política (2004) realiza uma densa análise sobre as contribuições que a Sociologia Política poderia oferecer aos estudos políticos brasileiros que, para o pesquisador, passaram a desenvolver uma aguda, unitária e pouco producente inclinação a perspectivas institucionalistas de análise e compreensão dos fenômenos políticos nacionais (PERISSINOTTO, 2004, p. 203-204). De acordo com Renato Monseff Perissinotto, amplamente apoiado nas reflexões e afirmações de Giovanni Sartori, verificamos que a Sociologia Política corresponde a um "hibrido interdisciplinar" no qual o pesquisador por ele influenciado deve se:

\begin{abstract}
orientar contra os reducionismos e deve conjugar em suas análises as variáveis típicas da Sociologia (as estruturas sociais) com as variáveis típicas da Ciência Política (as estruturas políticas). A Sociologia Política é, portanto, uma aceitação do fato óbvio, mas atualmente relegado ao esquecimento, de que os sistemas social, econômico e político são interdependentes. [...] A meu ver, a sua vantagem maior consiste em indicar uma orientação analítica geral que pode ser bastante proveitosa exatamente porque, de um lado, permite ao pesquisador reconhecer a importância das condições sociais subjacentes aos fenômenos políticos sem cair no reducionismo sociológico e, de outro, incorporar à análise as causas propriamente políticas desses fenômenos sem cair no "politicismo" e no "formalismo" presentes em alguns trabalhos recentes (PERISSINOTTO, 2004, p. 2005).
\end{abstract}

Considerando a particularidade de seu objetivo de investigação, Renato Monseff Perissinotto opta por analisar as "duas grandes vertentes teóricas que predominaram na análise do Estado brasileiro, ambas vinculadas à Sociologia Política: o marxismo e a sociologia weberiana" (PERISSINOTTO, 2004, p. 211), não focalizando assim, um conjunto amplo de estudos brasileiros produzidos na primeira metade do século $\mathrm{XX}$, afinal, segundo o pesquisador, estes resguardam a característica de serem "ensaísticos". Dessa forma, acreditamos que as reflexões propostas aqui podem auxiliar na dinamização daquilo que se compreende por uma Sociologia Política Brasileira, em especial acerca das possíveis ramificações intrínsecas à mesma 3 .

\footnotetext{
3 "Creio que essas questões só podem ser efetivamente abordadas por uma análise que pretenda ir além das dimensões institucionais e que não reduza a análise dos fenômenos políticos a procedimentos quantitativos ou meramente taxonômicos. Quanto a este último ponto, não estou defendendo aqui um retorno irresponsável ao ensaísmo existente nos primórdios da Ciência Social Brasileira. [...] É preciso dizer, contudo, que um ensaísmo erudito e criativo é fundamental para o avanço científico na medida em que sugere importantes questões de pesquisa. Se é verdade, como se costuma dizer, que tão importante quanto responder questões é formulá-las adequadamente, então uma cultura do ensaio pode ser benéfica para a produção científica. Foi esse, a meu ver, o papel cumprido por textos como Os Dono do Poder, Raízes do Brasil, Coronelismo, Enxada e Voto, entre vários outros" (PERISSINOTTO, 2004, p. 224).
} 
Elisa Pereira Reis, no recente artigo Sociologia Política e processos macrohistóricos (2015), realiza uma discussão ampla sobre a Sociologia Política de orientação macro histórica. Em suas análises, a autora pontua uma série de tipologias de estudos e pesquisas hoje desenvolvidos nas ciências sociais brasileiras que, em certa medida, poderiam ser alocados no campo da Sociologia Política; não por acaso, estes trabalhos não se distanciam da necessidade de compreender dinamicamente a política tendo como base a realidade social a qual ela se refere (REIS, 2015, p. 19-21). Para a autora, a Sociologia Política de orientação macro histórica "privilegia a análise de processos históricos, cujo propósito último é explicar ou interpretar transformações de longa duração" (REIS, 2015, p. 24). Segundo Elisa Pereira Reis, os trabalhos produzidos nesse "braço" da Sociologia Política apresentam uma recorrente preocupação "em se situar nos debates teóricos, reiterando a interdependência entre a análise de processos histórico-concretos e a elaboração teórica" (REIS, 2015, p. 24). No Brasil, para a autora, as pesquisas desenvolvidas por Florestan Fernandes acerca da especificidade da revolução burguesa em nosso país, por Werneck Vianna em relação à edificação de nossa força de trabalho e por Simon Schwartzman sobre os obstáculos de uma democracia liberal brasileira são emblemáticos quando temos em mente representantes nacionais de uma Sociologia Política macro histórica (REIS, 2015, p. 24). Todavia, anteriormente a estes estudos produzidos após a década de 1960, Elisa Pereira Reis afirma que certamente tínhamos "uma tradição de grandes interpretações históricas que nos inspiravam em maior ou menor grau" (REIS, 2015, p. 22-23). Sendo assim, ao passo que consideramos as afirmações da estudiosa, temos certo grau de liberdade para dimensionar que Oliveira Vianna é um importante componente dessa tradição ${ }^{4}$.

Considerando a perspectiva de ensaísmo ratificado por Renato Monseff Perissinotto, acreditamos que é possível problematizá-la no sentido de que muitos trabalhos localizados "nos primórdios da Ciência Social Brasileira" trouxeram reflexões densas que, certamente, extrapolaram a condição de interessantes perguntas ou questões; por vezes, essas reflexões, amplamente pautadas em diagnósticos e visões sobre o Brasil, transformaram-se em políticas públicas, modelos institucionais e leis. Uma evidência dessa problemática liga-se às ideias e à trajetória política de Oliveira Vianna que, é válido destacar, serão focalizadas de maneiras diferentes neste artigo.

${ }^{4}$ Mesmo não mencionando Oliveira Vianna, a descrição de Elisa Pereira Reis acerca do que foi essa tradição de Sociologia Política no Brasil nos fornece elementos para acreditar na inserção do intelectual fluminense em meio a determinados estudiosos brasileiros anteriores a 1960; segundo a autora: "Lembro aqui obras que se tornaram clássicas entre nós como as de Buarque de Holanda (1936), Caio Prado Jr. (1943), Raimundo Faoro (1958), entre outros. Os trabalhos desses precursores se distinguem por um forte viés histórico, mas não constituem uma sociologia política no sentido mais canônico que falamos hoje de uma especialização sociológica. De qualquer forma, entre eles e os primeiros trabalhos de sociologia política macro histórica no Brasil há uma clara afinidade temática qual seja a complexa interação entre o Estado e os interesses sociais em disputa. Também é possível observar nessa tradição de análise a tendência a tomar o Estado nacional como um ator estratégico, diferentemente de perspectivas teóricas que o tomam primariamente como resultado das disputas sociais" (REIS, 2015, p. 23).

Em Debat: Rev. Dig., ISSNe 1980-3532, Florianópolis, n. 12, p. 110-135, jul-dez, 2014. 
Estas foram as nossas considerações iniciais acerca de uma definição de Sociologia Política e, mais interessante que isso, as interlocuções que esse campo disciplinar desenvolveu e ainda desenvolve com as ciências sociais brasileiras. Seguramente essas reflexões serão importantes para "enquadrarmos" com mais propriedade o objeto de investigações proposto neste artigo. Nos próximos tópicos, veremos como essas importantes dimensões circunscritas à Sociologia Política foram amplamente investigadas por Oliveira Vianna no momento em que ele buscou compreender a trajetória formativa do Brasil e, em nossa conclusão, ficará claro como conceitos e posições durkheimianas ajudaram-no a realizar essa tarefa.

\section{A Sociologia Política de Oliveira Vianna e a sua Interpretação sobre o Brasil: um Diagnóstico e o Vislumbre de um País Moderno}

Populações Meridionais do Brasil (1922) é o estudo clássico de Oliveira Vianna que claramente possui a intenção de edificar uma interpretação acerca da formação da sociedade brasileira e, consequentemente, dos caracteres que nos marcaram indelevelmente como um povo sui generis. Nesta obra, o autor busca no Brasil Colônia as raízes e as razões pelas quais somos incapazes de atuar de maneira impessoal no espaço público. Além disso, vemos neste estudo um dos primeiros usos da noção de patriarcalismo no Brasil, concepção esta que perpassou e ainda perpassa uma série de estudos brasileiros que buscam compreender a nossa formação, nossas especificidades como povo e as peculiaridades de nossa vida pública.

Um traço marcante do raciocínio de Oliveira Vianna nessa obra é a necessidade de explicar o Brasil não só por dimensões culturais, sociais e políticas. Para o autor, é relevante compreender o povo brasileiro considerando a terra, a natureza, a morfologia e a geografia do espaço no qual ele habitou e se constituiu. Através do pensamento do cientista brasileiro notamos o quão coercitivo foram as determinações morfológicas e geográficas no desenvolvimento de nossa sociedade e, principalmente, na formação de um tipo individual que carrega consigo marcas profundas. Em relação a esta posição analítica do autor, notamos claramente que Oliveira Vianna procurou atrelar a antropogeografia e a morfologia social aos seus estudos, para assim, entender a formação do Brasil, de seu povo, de suas instituições e de sua cultura social e política.

No Brasil Colonial, segundo Oliveira Vianna, houve uma autonomia exagerada do latifúndio que, por sua vez, impediu que o país caminhasse rumo à urbanização e à 
modernidade. Aqui, em um dado momento da colonização, a retirada de riquezas feita pela Metrópole era efetivada através da exploração da terra, dessa maneira, os investimentos nacionais ligavam-se exclusivamente com o desenvolvimento dos latifúndios e das atividades rurais. Adicionado a isso, verifica-se que o latifúndio não exigia redes complexas de indústrias, de produção e de transportes: tudo que se precisasse para a manutenção da vida e para a atividade agrícola era produzido no interior dos mesmos. Assim, a sociedade colonial brasileira é caracterizada por ter profundas raízes rurais, as quais dificultaram fortemente a edificação de nossos conglomerados citadinos, zonas urbanas ou cidades. Desta forma, nos mostra o autor, os grupos sociais presentes nas cidades estariam presos ao poder dos latifundiários, não possuindo assim, um "espírito corporativo", o que constitui uma problemática, afinal, não houve em nosso país a construção de corporações com uma "solidariedade moral ${ }^{5}$ ".

De acordo com o intelectual brasileiro, a morfologia territorial do Brasil conduziu a um tipo específico de organização econômica colonial, a qual impediu o desenvolvimento efetivo de nossas zonas urbanas e de nossa economia. Dessa maneira, Vianna afirma que os grupos sociais presentes nas cidades eram presos ao poder dos latifundiários, não possuindo assim, um "espírito corporativo", o que é extremamente deficiente justamente porque não há a constituição de corporações com uma "solidariedade moral". "Espírito corporativo" e "solidariedade moral" são duas características ausentes da população inerente ao Brasil Colônia. Segundo o pensador brasileiro, os domínios rurais, conformados em suas autossuficiências, limitaram nosso caminho rumo à modernização, fazendo com que se girasse aos seus redores todo o sentido do Brasil Colônia. Através desse diagnóstico, Oliveira Vianna, posteriormente, desenvolve nesta mesma obra algumas explicações sobre aquilo que nos caracteriza, dentre elas, destaca-se a simbiose clássica na qual está fundado o Brasil: a indistinção entre o púbico e o privado. Obviamente, a caracterização morfológica do Brasil

\footnotetext{
${ }^{5}$ Através de uma fala do intelectual fluminense, temos a possibilidade de visualizar a especificidade social e cultural de nossas zonas urbanas no Brasil Colônia: "Villas, aldeias, arraiaes, todas não passam, ainda agora, de agglomerações humanas em estagnação, e mortiças (VIANNA, 1938, p. 159). " E continua, "[...] as classes urbanas não gosam aqui nenhum credito - e só a classe rural tem importância. Deante dos grandes latifundiários não se erguem nunca como organizações autônomas e influentes: ao contrario, ficam sempre na dependência delles. Não exercem, nem podem exercer aqui, a funcção superior que exerceram, deante de olygarchia feudal, as communas medievaes. Falta-lhes para isto o espírito corporativo, que não chega a formar-se. São meros conglomeratos, sem entrelaçamentos de interesses e sem solidariedade moral [...]" (VIANNA, 1938, p. 159). Antes de encerrarmos essa nota é importante fornecer ao leitor uma informação de caráter procedimental: da mesma maneira como fizemos nessa última citação, optamos por preservar no decorrer do texto o estilo ortográfico da época na qual Oliveira Vianna escrevia e publicava as suas ideias com fins de evitar possíveis imprecisões, respeitando assim, a integridade das argumentações e das posições assumidas pelo intelectual fluminense.
}

Em Debat: Rev. Dig., ISSNe 1980-3532, Florianópolis, n. 12, p. 110-135, jul-dez, 2014. 
Colonial não é suficiente para explicar a criação deste paradigma clássico, afinal, paralelamente a ela o intelectual articula os conceitos de patriarcalismo e de espírito de clã para construir tal núcleo analítico. Contudo, não é possível compreender efetivamente essa indistinção entre o público $e$ o privado sem considerar a caracterização morfológica de nossa colônia tal como é apresentada por Vianna.

Em Populações Meridionais do Brasil, Oliveira Vianna constata que no Brasil Colônia não há uma instituição capaz de proteger os direitos coletivos em detrimento de dados agrupamentos sociais: "O homem que não tem terras, nem escravos, nem capangas, nem fortunas, nem prestígio sente-se aqui, praticamente, fóra da lei. Nada o ampara. Nenhuma instituição, nem nas leis, nem na sociedade, nem na família existe para a sua defesa" (VIANNA, 1938, p. 201). Segundo o autor, os homens que possuem uma instituição capaz de resguardar seus direitos "são, por isso, autônomos. São, por isso, livres. Sob a ação permanente dessa confiança interior, o caracter se abdura, se consolida, se crystalisa e adquire a infragibilidade do granito ou do ferro" (VIANNA, 1938, p. 201). A autossuficiência dos latifúndios gerou uma série de problemas para o desenvolvimento do país. Nesse espaço, a aplicabilidade das leis era feita pelo Senhor de Terras, dono do latifúndio e patriarca. Reside nesse diagnóstico do intelectual fluminense a afirmação de que na sociedade colonial brasileira a obediência era dirigida exclusivamente ao líder local, e não para as poucas instituições políticas existentes, aos líderes ligados ao poder central e aos homens da lei vinculados a nossa vida pública (VIANNA, 2005, p. 345).

Tal diagnóstico de Oliveira Vianna é relevante para entendermos aquilo que o autor denomina como espírito de clã. Tal conceito sintetiza um modo de agir por parte dos brasileiros que está diretamente vinculado à ideia de uma desobediência para com as leis e os regimentos inerentes à vida pública em detrimento de relações de compadrio oriundas dos anseios particulares e dos interesses ligados à vida privada (VIANNA, 2005, p. 225-226). Para o intelectual brasileiro, o espírito de clã só se constituiu graças ao desmedido poder exercido pelo senhor de terras e patriarca no interior dos latifúndios. E é nesse momento que ele articula aos seus escritos em Populações Meridionais do Brasil o conceito de patriarcalismo. Tal conceito tem o objetivo de explicar o tipo de formação familiar que predominou no Brasil Colônia ${ }^{6}$.

\footnotetext{
${ }^{6}$ Oliveira Vianna, já em Populações Meridionais do Brasil (1920), expõe uma definição bem acabada do poder patriarcal exercido durante o período colonial. Para ele, tal poder tem uma presença marcante em nossos caracteres como povo: "Na alta classe rural, o contrário. É imensa a ação educadora do pater- 
Oliveira Vianna não foi o primeiro autor a usar a concepção de patriarcalismo para compreender o Brasil. Joaquim Nabuco, por exemplo, já fazia algumas alusões a esta noção (NABUCO, 1890). No entanto, o patriarcalismo tal como foi utilizado pelo pensador fluminense revelou algumas conclusões a respeito do Brasil e de sua formação diferenciadas. Interessantemente, vemos em nosso Pensamento Social e Político posterior aos anos trinta a reverberação de uma noção de patriarcalismo muito próxima da utilizada por Oliveira Vianna. Evidência disso são os usos desse conceito feitos por Sérgio Buarque de Holanda, Victor Nunes Leal e Raymundo Faoro em importantes obras ligadas às Ciências Sociais Brasileiras, quais sejam, respectivamente, Raízes do Brasil (1936), Coronelismo Enxada e Voto (1948) e Os Donos do Poder (1958).

A exposição destas ideias inerentes à obra Populações Meridionais do Brasil é relevante para compreendermos o paradigma analítico e interpretativo cunhado por Oliveira Vianna sobre a realidade brasileira e sua formação. O que notamos nessas leituras do pensador fluminense é que elas convergem para o entendimento da problemática inerente a nossa vida pública; ou seja, é por motivos específicos (herança rural, espírito de clã e patriarcalismo) que possuímos uma extrema dificuldade de respeitar leis abstratas e atuar de modo impessoal em meio aos espaços públicos e à vida pública. Reside nessa questão, posteriormente abordada/retomada pelo intelectual niteroiense em seu pensamento, a necessidade de se edificar de maneira artificial em nosso país um Estado Forte, Centralizado, Interventor e de predisposições Corporativas que fosse regido por uma elite técnica altamente especializada e burocratizada.

Outra interessante questão presente no pensamento de Oliveira Vianna vinculase com a crítica que o intelectual estabelece em relação aos legados negativos de nosso passado colonial e os meios pelos quais é possível transformar, desenvolver e modernizar o Brasil. Vinculada a este importante debate interno ao pensamento de Oliveira Vianna são articulados e teorizados pelo pensador fluminense alguns relevantes

famílias sobre os filhos, parentes e agregados, adstritos ao seu poder. É o pater-famílias que, por exemplo, dá noivo às filhas, escolhendo- o segundo as conveniências da posição e da fortuna. Ele é quem consente no casamento do filho, embora já em maioridade. Ele é quem lhe determina a profissão, ou lhe destina uma função na economia da fazenda. Ele é quem instala na sua vizinhança os domínios dos filhos casados, e nunca deixa de exercer sobre eles a sua absoluta ascendência patriarcal. Ele é quem os disciplina, quando menores, com um rigor que hoje parecerá bárbaro, tamanha a severidade e a rudeza. Por esse tempo, os filhos têm pelos pais um respeito que raia pelo terror. Esse respeito é, em certas famílias, uma tradição tão vivaz, que é comum verem-se os próprios irmãos cadetes pedirem a bênção ao primogênito. Noutras, as esposas chamam 'senhor' aos maridos, e esses, 'senhoras' às esposas. O sentimento de respeito aos mais velhos e de obediência à sua autoridade, tão generalizado outrora no nosso meio rural, é também uma resultante dessa organização cesarista da antiga família fazendeira" (VIANNA, 2005, p. 100).

Em Debat: Rev. Dig., ISSNe 1980-3532, Florianópolis, n. 12, p. 110-135, jul-dez, 2014. 
temas e questões, como por exemplo: a especificidade do período monárquico no Brasil; a peculiaridade e a relevância do Corporativismo na nação brasileira; os atributos distintivos de um Direito do Trabalho, de uma Legislação Trabalhista e de um Direito Corporativo para o Brasil; as incongruências e inconsistências da Constituição Brasileira de 24 de Fevereiro de 1891; e, por fim, as características constitutivas de nossas instituições políticas. Diante destes caros temas e debates intrínsecos ao pensamento vianniano, escolhemos apenas dois para aqui realizar uma introdutória apresentação e análise acerca da percepção do pensador niteroiense sobre a possibilidade de se transformar e desenvolver o Brasil, quais sejam: a interpretação de Oliveira Vianna acerca da Constituição de 1891 e o debate por ele oferecido sobre o Corporativismo no Brasil. Contudo, nossa análise não pode ser feita sem, minimamente, apresentar a crítica do pensador fluminense à herança colonial brasileira e a necessidade de superá-la para, dessa forma, se modernizar nosso país.

Na obra Instituições Políticas Brasileiras (1949), Oliveira Vianna trabalha de modo extensivo com as noções de Direito Costumeiro e de Direto Constitucional. O primeiro está estreitamente vinculado com os costumes, tradições, representações e regras coletivas experimentadas cotidianamente pela sociedade ou pelo "povo-massa" que foram processualmente construídos no Brasil em bases não institucionais, ou seja, em meio à realidade social, objetiva e material na qual a população brasileira esteve inserida desde o período colonial. Já o segundo, no entanto, foi criado e desenvolvido por nossas elites sem levar em consideração aquilo que realmente somos. Segundo o pensador brasileiro, o Direito Costumeiro tem mais força que o Constitucional por estar intimamente ligado com os modos de agir, sentir e pensar de um determinado povo (ou seja, sua cultura). Este vínculo tão caro para o intelectual fluminense é, segundo ele, negado por nossos juristas no momento em que estes comentam ou edificam leis para o Brasil. De acordo com Oliveira Vianna, uma perspectiva metodológica moderna, em seu tempo, destinada a fornecer amparo técnico e científico à ciência política e ao trabalho jurídico deve primar por uma análise objetiva do real, articulando assim, os caracteres próprios do costume e do comportamento humano de uma determinada sociedade às leis e aos códigos que regem suas instituições (VIANNA, 1999, p. 49).

O não vínculo entre as especificidades culturais de um povo e a forma das leis, assim como a problemática circunscrita à importação de complexos culturais, serão as bases da justificativa de Oliveira Vianna a respeito da não predisposição da sociedade brasileira a formas liberais e democráticas de governo (FONTANA; FEREZIN, 2013, p. 
72-96). Além disso, o pensador recorrerá ao estudo do desenvolvimento histórico de outras sociedades para afirmar que apenas alguns processos específicos de formação levam à conformação de sociedades democráticas (o Brasil, segundo o intelectual fluminense não seria um desses agrupamentos sociais justamente por conservar na sua trajetória histórica as permissivas e indeléveis marcas do processo colonizador). Para o pensador niteroiense, um Estado-Nação - de base democrática pós Revolução Francesa - só pôde existir graças a uma herança histórica que possibilitou a emergência de um sistema de governo como esse. O grande problema dos povos modernos, segundo o autor, é justamente a intenção que eles possuem de ajustar seus costumes, suas características distintivas e suas tradições às bem sucedidas formas de organização política que, por vezes, foram fundadas em preceitos e condições extremamente específicas. Para Oliveira Vianna, esta é a causa "íntima da crise do Estado Moderno" que, em dados momentos, se expressa em Cartas Constitucionais e Desenhos Institucionais inadequados e incongruentes quando comparados à efetiva realidade social, política, cultural e econômica de um país.

No caso brasileiro, a herança colonial não só restringia e impedia a construção de um governo e de uma política de cunho liberal e democrático. Notamos também que o processo particular de formação do Brasil esteve intrinsecamente relacionado com um peculiar antiurbanismo, com a não constituição de classes médias trabalhadoras, com a enorme predisposição à condição de país agroexportador e, consequentemente, com o atraso no processo de industrialização. Dessa forma, podemos afirmar que a experiência colonial e o seu legado (dentre outras coisas, o Direito Costumeiro dela decorrente) são barreiras que impelem a fomentação de uma série de atributos e características que amplamente definem aquilo que é uma sociedade moderna (ou seja, desenvolvida em seus aspectos sociais, econômicos, políticos, culturais, etc.).

Ao pautarmo-nos na interpretação do intelectual fluminense percebemos que diferentemente de alguns países da Europa, no Brasil, as raízes culturais de nossa formação como povo são outras e excluem radicalmente uma vida pública regulada e ajustada por princípios políticos liberais e democráticos de governo e de participação; ou ainda, em posições liberais acerca das dinâmicas econômicas, dos processos de industrialização e dos movimentos de construção e organização de um operariado urbano-industrial (FONTANA; FEREZIN, 2013, p. 79-84). Para o autor, o espírito de clã, o poder exacerbado do latifúndio, o predomínio da atividade agrícola monocultora para exportação, a substituição de um poder oficial pelo permissivo reconhecimento da 
autoridade do senhor de terras (latifundiário) e a ausência efetiva de uma entidade reguladora impediram e, segundo a sua visão, ainda em seu tempo, impediam a construção de um Brasil efetivamente moderno nas mais variadas dimensões.

Oliveira Vianna, ao passo que destacava as dinâmicas existentes entre a formação dos Estados Modernos e os incongruentes desenhos e formas institucionais, legais e governamentais recorrentemente requeridos por eles, expõe uma das chaves explicativas mais desenvolvidas em sua obra que, por vezes, justificam a ideia de que o Brasil para se modernizar necessita de específicas formas de governo, particulares instituições e, principalmente, leis atentas e preocupadas com as peculiaridades do Direito Costumeiro inerente à população brasileira. A expressão máxima dessa leitura e interpretação, de acordo com a nossa opinião, foi transposta pelo intelectual fluminense na obra $O$ Idealismo da Constituição (1927) com uma ácida crítica à Carta Constitucional Republicana de 1891.

De modo geral, o autor defende que a Carta Magna de 24 de Fevereiro de 1891, nossa primeira Constituição Republicana, era incompatível com a realidade social, política, cultural e econômica da sociedade brasileira. Dentre outras coisas, ela resguardava excessivamente princípios liberais alheios à mentalidade brasileira (VIANNA, 1927, p. 85); a mesma era, infortunadamente, inspirada de maneira profunda na Constituição Inglesa e na Carta Magna Estadunidense (VIANNA, 1927, p. 37-41); ela foi feita por uma elite desconhecedora das especificidades do Brasil e, sobretudo, de seu povo (VIANNA, 1927, p. 21-24); nossa Carta Magna de 1981 protegia e resguardava os permissivos interesses e abusos oligárquicos de dados segmentos sociais; e, por fim, ela era extremamente inocente quanto à eficácia da lei escrita (para o intelectual fluminense, nossos juristas e legisladores acreditavam que a lei por si só produziria um efeito positivo e transformador na sociedade) (VIANNA, 1927, p. 25). De maneira geral, para Oliveira Vianna, a Constituição de 1891 estava em completo desacordo com a realidade brasileira (VIANNA, 1927, p. 36).

Todo o problema vinculado com a dificuldade de se constituir leis e instituições adequadas no Brasil, questão germinal da obra $O$ Idealismo da Constituição, também aparece, não por acaso, em muitos estudos de Oliveira Vianna. Em Instituições Políticas Brasileiras (1949), última obra publicada em vida por Oliveira Vianna, encontramos a reunião das principais argumentações presentes em sua produção intelectual. Dentre os muitos temas, interpretações, raciocínios e ideias recuperadas, o autor fluminense afirma que as leis brasileiras cunhadas em 1891, assim 
como o desenho de nossas instituições políticas, foram permissivamente inspiradas nas formas institucionais e legais de outras nações. Assim, para o autor, muitos dos arranjos institucionais e legais implementados em nosso país fracassaram e não produziram um efeito esperado justamente porque não consideraram as particularidades do povo brasileiro. Ou seja, uma contradição entre "país real e país legal”; uma incongruência entre "forma e conteúdo"; ou ainda, uma incoerência entre as "ideias e o lugar" (SCHWARZ, 2000, p. 26, 27, 28).

Diante desse quadro interpretativo acerca dos problemas decorrentes do legado colonial que dificultavam, quando não impediam, o processo de modernização do Brasil e sobre os empecilhos de se produzir eficazes e condizentes leis e instituições em nosso país que superassem o legado colonial, Oliveira Vianna propõe alguns caminhos para se desenvolver a nação brasileira. Dentro das soluções possíveis, nenhuma exclui o reconhecimento, por parte do autor, da necessária autoridade do Estado para se transformar de modo profundo o Brasil. Ou seja, para o intelectual fluminense, a nação brasileira só se desenvolveria efetivamente através da ação de um tipo de Estado forte, centralizado, interventor e de autoridade amplamente reconhecida capaz de construir através de políticas públicas, instituições e leis adequadas - as etapas constitutivas de um processo modernizador de nação. Em meio às funções que este tipo de poder central deveria desempenhar, a regulamentação do trabalho no Brasil, assim como da classe trabalhadora brasileira, assume um importante papel na obra e na vida política de Oliveira Vianna. Na sua vida política podemos destacar o período em que ele trabalhou como consultor jurídico no Ministério do Trabalho, Indústria e Comércio (de 1932 até 1940) tendo como função a construção dos pilares do Direito Trabalhista Brasileiro (MENEZES, 1997, p. 188). Já em seu pensamento, podemos enfatizar as discussões que ele desenvolveu acerca da real efetividade de um Corporativismo no Brasil. E é em relação a este último ponto que deteremos nossas próximas observações.

De acordo com Oliveira Vianna, em Populações Meridionais do Brasil, verificamos que a ausência de solidariedade é, desde o início de nossa formação como povo, algo latente na sociedade brasileira. Tal deficiência justificaria a não constituição de corporações comerciais, conglomerados industriais e localidades efetivamente urbanas no Brasil. Nesse sentido, para o autor, a criação dessas organizações autônomas, principalmente as corporações profissionais, deveria ser realizada artificialmente pelo Estado Brasileiro, para assim, o Brasil se tornar um país moderno, complexo e, principalmente, integrado mesmo em meio ao processo de industrialização 
e de desenvolvimento econômico (para Oliveira Vianna a economia deveria ser guiada pelo Estado Brasileiro porque, dentre vários motivos, as atividades econômicas quando não reguladas produzem conflitos e problemas sociais capazes de travar o processo de modernização de um país). Na forma de sindicatos, essas organizações profissionais seriam constituídas e orientadas pelo Estado (QUEIROZ, 1975, p. 112-113).

Para Oliveira Vianna a importância das organizações profissionais vincula-se com a necessidade de se constituir uma efetiva solidariedade e integração entre a população brasileira. Adicionado a isso, também verificamos o quão importante é o papel do Estado no processo de edificação dos sindicados profissionais e nessa tentativa de se construir um corporativismo no Brasil modelado pelas especificidades de nosso país e de nosso povo. Oliveira Vianna não aborda enfaticamente o debate voltado para a compreensão das noções de Corporações, Organizações Profissionais, Corporativismo, Estado Corporativo e Sindicalismo em suas obras iniciais ${ }^{7}$. No entanto, a série de estudos intitulada de Problemas $^{8}$ publicada pelo autor é uma boa opção para apreender com mais propriedade as concepções do intelectual fluminense acerca desse tema. Dessa forma, para nossas análises, selecionamos a obra Problemas de Organização e Problemas de Direção (1952), última obra da série, por conservar posições mais maduras e acabadas acerca da temática aqui abordada.

Nesta obra nós podemos verificar um elemento a mais que explica a necessidade de uma sociedade conformada em corporações. Para o autor, o individualismo oriundo de nosso processo de formação deve ser contornado, dessa forma, as organizações sindicais e corporativas teriam um papel fundamental ${ }^{9}$. Somado a isso, o excessivo crescimento do individualismo na sociedade é tratado por Oliveira Vianna como um problema a ser combatido. Sendo assim, o individualismo e o egoísmo inerentes aos empresários, industriais, empregados e operários mostra-se uma extensão do constante insolidarismo presente em nossa sociedade. Levando em consideração essa perspectiva,

\footnotetext{
${ }^{7}$ Populações Meridionais (1922), O Idealismo na Evolução Política do Império e da República (1922), Evolução do Povo Brasileiro (1923), O Ocaso do Império (1925) e O Idealismo da Constituição (1927).

${ }^{8}$ Problemas de Política Objetiva (1930), Problemas de Direito de Corporativo (1938), Problemas de Direito Sindical (1943) e Problemas de Organização e Problemas de Direção (1952).

9 "Esta gravitação para o grupo, que estamos assinalando como objetivo polar dos nossos métodos educativos - diga-se de passagem - não visa absorver o indivíduo no grupo, como pretendiam certas doutrinas universalistas ou totalitaristas (Spen, Spengler, Sprangers, Forbenius, Boas, etc.); mas, apenas, completar, em nosso povo, o indivíduo, isto é, dar-lhe uma consciência mais viva e clara da sua solidariedade com o grupo a que pertence, de modo a nos constituirmos numa sociedade de homens, senão voltados, como sacerdotes, ao bem comum, pelo menos sabendo sentir, com vivacidade, o interesse geral, o bem da coletividade, da classe, da localidade, da Nação. Presentemente, no Brasil, existem três centros de educação do homem brasileiro neste sentido: a) as forças armadas; b) as formações escoteiras; c) as organizações sindicais e corporativas" (VIANNA, 1974, p. 27-28).
}

Em Debat: Rev. Dig., ISSNe 1980-3532, Florianópolis, n. 12, p. 110-135, jul-dez, 2014. 
notamos que para o autor o Corporativismo é uma solução viável para contrariar esse quadro problemático que ele enxerga em nosso país (VIANNA, 1974, p. 30, 31, 34).

Essas posições de Oliveira Vianna sobre os mecanismos necessários ao processo de modernização do Brasil, ou seja, acerca da ação de um tipo de Estado forte, centralizado, interventor e de cunho corporativo foram - além de importantes para a vida política e a institucionalização/regulamentação do trabalho no país - relevantes para complexificar o debate voltado e esse tema em nosso Pensamento Social e Político. Em certa medida, estas ideias de Oliveira Vianna foram embrionárias. Bolivar Lamounier (1978), Boris Fausto (2001), Evaldo Vieira (1978) e Wanderley Guilherme dos Santos (1975), grandes estudiosos vinculados à Ciência Política Brasileira, teorizaram acerca da corrente intelectual denominada de Pensamento Autoritário Brasileiro afirmando que o seu nascimento esteve intimamente ligado com as elaborações teóricas de alguns autores que, sobretudo, reconheciam valorosamente a autoridade do Estado como um requisito necessário à transformação do Brasil. Mesmo resguardando dadas inconsistências em suas posições acerca do que foi o Pensamento Autoritário Brasileiro (FONTANA; FEREZIN, 2014, p. 20-21), estes pesquisadores destacam as ideias de Alberto Torres e de Oliveira Vianna como fundamentais e germinais para a edificação dessa corrente de pensamento em nosso país.

\section{A Ligação entre o Pensamento Vianniano e determinados Conceitos, Noções, Ideias e Paradigmas Durkheimianos}

Este tópico do artigo liga-se profundamente aos resultados da dissertação intitulada de A Presença de Émile Durkheim em Oliveira Vianna: Contribuições ao Pensamento Social e Político Brasileiro, defendida em março de 2013. De modo geral, acreditamos que essa pesquisa demonstrou que há importantes vínculos entre o pensamento de Oliveira Vianna e o de Émile Durkheim, nesse sentido, determinadas ideias do sociólogo francês, ao passo que foram agregadas por Vianna, ofereceram ao pensamento vianniano significativas contribuições. Estas contribuições são visíveis quando pensamos em alguns conceitos e noções particulares, são eles: os conceitos de Consciência Coletiva e de Solidariedade Social, e as noções de Morfologia Social, de Estado e de Corporativismo. De antemão, vale destacar que todas essas conceitualizações durkheimianas encontram-se atreladas ao diagnóstico e ao prognóstico edificado por Vianna acerca da nação brasileira; ou seja, vinculam-se a 
intepretação social do intelectual brasileiro que fundamentou a sua visão analítica e prognóstica acerca das dimensões organizativas, institucionais e políticas do Brasil.

De maneira ampla e estrutural, verifica-se que a leitura durkheimiana sobre a Terceira República Francesa e a percepção de Oliveira Vianna acerca da Formação do Brasil possuem um importante ponto em comum: ambos os autores identificavam em seus tempos e contextos históricos processos sociais, econômicos, políticos e culturais de desintegração e conservavam sobre os mesmos um olhar de preocupação. No caso de Émile Durkheim, a modernização inerente à sociedade francesa geraria processos que iam contra a integração efetiva dessa sociedade; além disso, o autor via nesse momento da História da França a possibilidade de unificar efetivamente a sua nação (vide o papel da educação para o autor). Oliveira Vianna constata no Brasil, por uma série de motivos já expostos, a inexistência de uma solidariedade e de uma união entre os indivíduos. Nesse sentido, percebe-se que não é por acaso que alguns conceitos durkheimianos puderam ser utilizados pelo intelectual brasileiro no momento em que ele estudou a formação do Brasil (FONTANA, 2013, p. 57).

Em relação aos conceitos de Consciência Coletiva e de Solidariedade Social, verificam-se semelhanças entre aqueles ratificados no pensamento durkheimiano e os que estavam dispostos em dadas obras viannianas. As marcações do intelectual brasileiro em alguns manuais de sociologia e estudos durkheimianos sinalizavam que ele realizou importantes leituras acerca destas conceitualizações. Para fortalecer essa hipótese, comparamos determinadas afirmações de Oliveira Vianna que empregavam estes conceitos a marcações que o mesmo tinha realizado em certos livros, tais como: Sociologie [1939] de Marcel Déat e La Solidarité Sociale [1907] de G. L. Duprat $\left(\right.$ FONTANA, 2013, p. 74) ${ }^{10}$. De maneira geral, estas conceitualizações, do modo como Oliveira Vianna as utilizou, foram empregadas no sentido de destacar o alto grau de desintegração social, cultural e política da sociedade brasileira desde a sua formação (vide a conceituação de insolidarismo cunhada pelo intelectual brasileiro).

Já as concepções de Estado e de Corporativismo existentes na obra de ambos os autores resguardam um sentido muito próximo. Assim, verificou-se comparativamente a partir das marcações de Oliveira Vianna na obra De la Division du Travail Social (1932), através do livro Lições de Sociologia (1912) e por meio de determinados

\footnotetext{
10 Os estudos de Émile Durkheim e os manuais introdutórios consultados por nós como fontes das marcações de Oliveira Vianna - que nos ajudaram a visualizar com mais propriedade a origem das conceptualizações e das noções durkheimianas empregadas pelo intelectual brasileiro - estão disponíveis no acervo do Museu Casa de Oliveira Vianna, Niterói-RJ.
}

Em Debat: Rev. Dig., ISSNe 1980-3532, Florianópolis, n. 12, p. 110-135, jul-dez, 2014. 
estudos viannianos - que para Émile Durkheim e Oliveira Vianna deve haver e deve ser priorizado um vínculo profundo entre o Estado e a Sociedade. Nesse sentido, para eles, o Estado deve agregar as representações, os costumes, as tradições e as regras de um determinado povo ou nação. Assim, nota-se que para os autores o Estado é a extensão de uma dada coletividade e sua especificidade deveria resguardar as características constitutivas do povo ao qual ele se dirige. No caso de Oliveira Vianna, como já observamos, a incompatibilidade entre tipos de Estados e o Direito Costumeiro de determinadas sociedades geraria grandes mazelas (FONTANA, 2013, p. 109).

Admitir essa relevante ligação entre o Estado e a Sociedade existente no pensamento de ambos os autores parece uma grande obviedade. Contudo, é só a partir disso que se consegue compreender os motivos pelos quais Oliveira Vianna afirma em Instituições Políticas Brasileiras (1949) que determinadas civilizações europeias só estavam experimentando um regime democrático porque possuíam um Direito Costumeiro diferente do nosso. Ou seja, para o autor, a peculiaridade da formação destas civilizações possibilitou o nascimento de uma Consciência Nacional forte compatível com uma forma de organização democrática de governo. Assim, segundo o pensador brasileiro, as especificidades de um determinado poder central dependem das características existentes na coletividade que ele regula. De modo mais claro, a natureza do Estado deve se adequar, dessa forma, às particularidades da sociedade de que ele faz parte. Essa questão para nós é de fundamental importância justamente porque ela nos auxilia na tarefa de dimensionar com mais propriedade os aspectos sócio-políticos circunscritos ao pensamento vianniano.

Vinculada a essa percepção acerca do que deveria ser o Estado, constata-se que a noção de Corporativismo presente no pensamento de Oliveira Vianna e no de Émile Durkheim representa a extensão do modo como os autores observam e interpretam suas realidades. Sendo assim, para eles, o Corporativismo é uma solução viável para contrariar o quadro negativo que enxergam em suas sociedades, afinal, um projeto político corporativista resguardaria a capacidade de equilibrar forças antagônicas desagregativas em conjunturas históricas de profundas transformações ou em contextos nos quais é necessário construir artificialmente a integração social e política de um país (FONTANA, 2013, p. 109). Além disso, é válido lembrar, que a percepção que ratifica uma falta de integração, coesão e união entre os indivíduos de uma mesma sociedade é resultado, no caso de Émile Durkheim, de um processo de modernização. Já, para Oliveira Vianna, essa percepção é fruto das especificidades circunscritas à formação do 
Brasil, as quais impediram a edificação de um processo bem acabado de desenvolvimento, urbanização e industrialização (FONTANA, 2013, p. 130).

Também observamos que o conceito de Morfologia Social empregado por Oliveira Vianna em alguns de seus trabalhos é altamente inspirado em posições durkheimianas. Em grande medida, estas perspectivas de Émile Durkheim foram lidas e sublinhadas pelo intelectual brasileiro no manual intitulado Sociologie Générale (1912), de Gaston Richard. Para o intelectual francês, a Morfologia Social é uma área da Sociologia que leva em consideração as características naturais, organizacionais e materiais de uma dada sociedade para melhor compreender seus atributos sociais, culturais, políticos e morais. Realizar pesquisas nessa área exige rigor e, para Émile Durkheim, a melhor maneira de fazer isso é retomar as formas primeiras das coletividades que se pretende analisar. De maneira geral, observamos que o pensador brasileiro desenvolveu estes pressupostos em determinados estudos, especialmente em Populações Meridionais do Brasil, no qual ele faz questão de enfatizar a importância de retornar a uma de nossas primeiras formas organizacionais (Brasil Colonial) para compreender nossas especificidades sociais, culturais, econômicas e políticas sem desconsiderar as bases materiais em que se edificou o processo de formação do Brasil aspectos geográficos, naturais e organizacionais - (FONTANA, 2013, p. 134).

De modo geral, estas são as conceitualizações e as noções durkheimianas que ajudaram Oliveira Vianna a explicar o Brasil. Posteriormente, nos deteremos à exposição de como essa aproximação entre os dois autores foi relevante para a construção de uma Sociologia Política intrínseca ao pensamento vianniano; principalmente quando temos em mente a constituição de um tipo singular de interpretação sobre o Brasil que engloba as dimensões sociais e materiais do país, para assim, compreender seus problemas políticos e, sobretudo, os empecilhos que dificultam o seu processo de modernização.

\section{Conclusão}

Considerando a definição de Sociologia Política que construímos e as análises que desenvolvemos - tanto vinculadas à interpretação de Oliveira Vianna sobre o Brasil, quando acerca da especificidade das ligações existentes entre o pensamento vianniano e determinadas noções e conceitos produzidos por Émile Durkheim - é possivel indagar: qual a relevância dos usos de conceitualizações durkheimianas 
realizados por Oliveira Vianna na constituição da dimensão sócio-política de seu pensamento? Para nós, a presença das ideias de Émile Durkheim no pensamento de Oliveira Vianna se mostrou producente na atividade de edificar a sua interpretação e o seu diagnóstico sobre o Brasil que, por sua vez, compõem a base de toda sua análise acerca dos problemas políticos do país e dos empecilhos que inviabilizam um efetivo processo de modernização da sociedade brasileira; ou seja, relevante para construir os pilares indispensáveis à confecção de um estudo intrínseco à Sociologia Política (que, em linhas gerais, pressupõe uma leitura, um diagnóstico ou uma interpretação do social, para assim, compreender de modo diferenciado, completo e dinâmico a política e a vida pública de uma dada coletividade). Apreender e caracterizar os ditames sociais nas suas mais variadas dimensões para, dessa forma, entender e especificar a particularidade da política, do Estado e das instituições brasileiras foi uma tarefa desempenhada amplamente por Oliveira Vianna que claramente liga-se com aquilo que entendemos por Sociologia Política. Profundamente vinculado a isso, vale destacar que essa tarefa foi dinamizada e complexificada ao passo que o intelectual brasileiro fez uso de algumas conceitualizações, ideias e noções produzidas por Émile Durkheim.

No momento em que usa os conceitos de consciência coletiva e de solidariedade social para apreender o grau de desintegração inerente ao Brasil, Oliveira Vianna ratifica postulados durkheimianos e mostra como essa característica da formação brasileira infere, incisivamente, na maneira pela qual encaramos aquilo que é público e aquilo que é privado, ou ainda, no modo como avaliamos e requeremos a tipologia e o formato de nossas instituições. Não por acaso, e mais uma vez se apoiando em ideias alinhadas ao pensamento durkheimiano, Oliveira Vianna acredita que para se modernizar o Brasil é necessário construir um Estado de autoridade amplamente reconhecida, com predisposições corporativas e capaz de regular nossas organizações trabalhistas, nossas atividades econômicas e projetar uma legislação voltada ao mundo do trabalho adequada à realidade nacional.

Somado a isso, notamos que o uso que o intelectual fluminense faz da noção de Morfologia Social - outro ponto profundamente inspirado em posições durkheimianas atrela-se enfaticamente com a necessidade de mensurarmos com mais propriedade as características sociais do Brasil. Por mais que esta conceitualização ratifique a importância de estudarmos profundamente os atributos estruturais, morfológicos, geográficos, físicos e materiais de uma população e de seu território, nós observamos que tal tarefa só é imprescindível para, a partir dela, se edificar observações e Em Debat: Rev. Dig., ISSNe 1980-3532, Florianópolis, n. 12, p. 110-135, jul-dez, 2014. 
conclusões que proporcionem um entendimento profundo das predisposições sociais, culturais, políticas e morais de uma dada realidade social.

Outro relevante ponto liga-se com o fato de que os trabalhos sobre o Brasil e sua formação social, ao passo que se articularam com esse modo de compreender e estudar a realidade social e política brasileira considerando suas dimensões sociais para avaliar e entender a peculiaridade de suas instituições políticas, ganharam com os estudos iniciais de Oliveira Vianna um fôlego novo e diferenciado: seja por uma questão de métrica, seja por uma questão de conteúdo e afinidades interpretativas. Em termos de métrica, verificamos o aparecimento de uma série de trabalhos preocupados em revisitar nossa trajetória enquanto colônia para dimensionar muitas de nossas positivas e negativas especificidades. Já relacionado a conteúdo, notamos em muitos estudos de nosso pensamento social e político, posteriores aos anos de 1920, a ratificação de um diagnóstico sobre o Brasil que, quando não idêntico, apresentava-se muito próximo ao de Oliveira Vianna, ou ainda, resguardava elementos cruciais da visão que o mesmo construiu sobre o Brasil. Parte dessas observações ancora-se, por exemplo, na tese das Linhagens de Pensamento Político Brasileiro edificada por Gildo Marçal Brandão no ano de 2007, em especial na linhagem denominada de Idealismo Orgânico, da qual Oliveira Vianna seria o precursor ${ }^{11}$. Ou ainda, como afirma José Murilo de Carvalho em A Utopia de Oliveira Vianna (1991)

\footnotetext{
${ }^{11}$ Gildo Marçal Brandão, na tentativa de sintetizar as principais linhagens contidas em nosso Pensamento Político identifica, em um conjunto relativamente amplo delas, duas que exprimem uma forte preocupação com o tema da relação entre a Sociedade e o Estado a partir do binômio "amor ao Estado" (idealismo orgânico) ou "amor à sociedade" (idealismo constitucional); dentre outras existentes, estas seriam as duas principais famílias intelectuais viventes no Pensamento Político Brasileiro. Para Brandão, apesar de existirem - entre ideias e intelectuais - rupturas, continuidades, progressismos, regionalismo, regressionismos, direitas e esquerdas ao longo da história das ideias no Brasil, duas linhagens balizaram o debate em meio ao pensamento político nacional: o idealismo orgânico e o idealismo constitucional. Estes termos, originalmente cunhados por Oliveira Vianna, são emprestados por Brandão com sentido renovado, pelos quais ele demonstra que as duas linhagens fundamentais do pensamento político brasileiro - a conservadora e a liberal - teriam como embriões, respectivamente, o idealismo orgânico e o idealismo constitucional. Para Brandão, as linhagens do pensamento político constituem diferentes posições ideológicas frente o papel e a função do Estado. No debate político brasileiro, os idealistas orgânicos entendem que a sociedade possui uma natureza inclinada para fragmentação, dispersão e debilidade em suas formações associativas. $O$ idealista orgânico ratifica a percepção de que a nação - mal formada - necessita ser tutelada e fortemente administrada. Para uma sociedade inorgânica, a solução seria um Estado centralizado, forte, de autoridade reconhecida e capaz de organizar a sociedade: "A imagem do Brasil que emerge do pensamento conservador é a de que esse é um país fragmentado, atomizado, amorfo e inorgânico, uma sociedade desprovida de liames de solidariedade internos e que depende umbilicalmente do Estado para manter-se unida. Nesta terra de barões, onde 'manda quem pode e obedece quem tem juízo', o homem comum só costuma encontrar alguma garantia de vida, liberdade e relativa dignidade se estiver a serviço de algum poderoso. Fora disso, estará desprotegido - a não ser que o Estado intervenha. Ao contrário da Europa e dos Estados Unidos, aqui o Estado não deveria ser tomado como a principal ameaça à liberdade civil, mas como sua única garantia (BRANDÃO, 2010, p. 46-47)". Para a argumentação aqui desenvolvida é relevante destacar que na definição de Idealismo Orgânico, tal
}

Em Debat: Rev. Dig., ISSNe 1980-3532, Florianópolis, n. 12, p. 110-135, jul-dez, 2014. 
A razão mais importante para uma visita desarmada [à obra do intelectual fluminense] é a inegável influência de Oliveira Viana sobre quase todas as principais obras de sociologia política produzidas no Brasil após a publicação de Populações Meridionais do Brasil [1920]. Dele há ecos mesmo nos autores que discordam de sua visão política. A lista é grande: Gilberto Freyre, Sérgio Buarque, Nestor Duarte, Nelson Werneck Sodré, Victor Nunes Leal, Guerreiro Ramos e Raymundo Faoro, para citar os mais notáveis. Até mesmo Caio Prado lhe reconhecia o valor, ressalvando as críticas. Tal repercussão indica a riqueza das análises de Oliveira Vianna e justifica o esforço de revisitá-las (CARVALHO, 1991, p. 83) ${ }^{12}$.

Oliveira Vianna estabeleceu em nosso Pensamento Social e Político influências teóricas e conceituais de extrema importância, as quais se ligaram de maneira discreta ou contundente a vários estudos que buscaram compreender a formação da sociedade brasileira em seus diversos aspectos (com merecido destaque aos sociais, culturais e políticos); as palavras acima citadas de José Murilo de Carvalho refletem em grande medida essa questão. Nesse sentido, tanto Oliveira Vianna quanto os intelectuais que partilham de seus postulados, em especial aqueles inspirados nas interpretações voltadas às particularidades formativas do Brasil e as consequências decorrentes das mesmas (diagnóstico e prognóstico circunscritos ao pensamento vianniano), parecem compor ou integrar um campo de estudo que se convencionou chamar de Sociologia Política. Considerando as especificidades regionais e as afinidades teórico-intelectuais as quais as posições e as perspectivas de Oliveira Vianna e de seus seguidores estão atreladas, nos parece producente especificar ainda mais esse conjunto de ideias e autores caracterizando-os como pertencentes a uma vertente particular da Sociologia Política Brasileira.

como é proposta por Brandão na citação anterior, ratifica-se em grande medida o diagnóstico e o prognóstico vianniano constantemente evidenciado por nós neste artigo.

${ }_{12}$ Nessa mesma direção, como afirma Ricardo Silva no artigo intitulado Liberalismo e democracia na Sociologia Política de Oliveira Vianna (2008), verificamos que: "Na história do pensamento político brasileiro do século $\mathrm{XX}$, poucos autores têm reunido tão amplamente as condições justificativas do qualificativo de "clássico" do que o sociólogo e historiador fluminense Francisco José Oliveira Vianna. Suas idéias tiveram impacto quando originalmente difundidas e revelaram persistência em épocas seguintes, constituindo-se, até os dias atuais, em objeto da atenção de historiadores das idéias e cientistas sociais das mais diversas orientações" (SILVA, 2008, p. 239).

Em Debat: Rev. Dig., ISSNe 1980-3532, Florianópolis, n. 12, p. 110-135, jul-dez, 2014. 


\section{Referências}

CARVALHO, José Murilo de. A Utopia de Oliveira Viana. Revista Estudos Históricos, Rio de Janeiro, Volume VII, No. 1, 1991. Disponível em:

<http://bibliotecadigital.fgv.br/ojs/index.php/reh/article/view/2310 >. Acesso em: 12 jun. 2014.

BRANDÃO, Gildo Marçal. Linhagens do pensamento político brasileiro. São Paulo: Hucitec, 2010.

CUVILLIER, A. Introduction à la Sociologie. Paris: Libraire Armand Colin, 1936. Disponível em: Acervo do Museu Casa de Oliveira Vianna. Acesso em: 14/07/2011.

DÉAT, Marcel. Notions de Sociologie. 10ª Ed Paris: Libraire Félix Alcan, 1939.

Disponível em: Acervo do Museu Casa de Oliveira Vianna. Acesso em: 14/07/2011.

DUPRAT, G. L. La Solidarité Sociale: ses causes, son évolution, ses conséquences. Paris: Octave Doin, Éditeur, 1907. Disponível em: Acervo do Museu Casa de Oliveira Vianna. Acesso em: 14/07/2011.

DURKHEIM, Émile. A divisão do trabalho social. Trad. Eduardo Brandão. São Paulo: Martins Fontes, 1995.

As regras do método sociológico. $17^{\mathrm{a}}$ Ed. São Paulo: Companhia Editora Nacional, 2002.

Educação e Sociologia. $8^{\text {a }}$ Ed. São Paulo: Melhoramentos, 1972.

. De la Division du Travail Social. $6^{a}$ Ed. Paris: LABRAIRE FÉLIX ALCAN, 1932. Disponível em: Acervo do Museu Casa de Oliveira Vianna. Acesso em: 07/07/2011.

Lições de sociologia: a Moral, o Direito e o Estado. São Paulo: Editora da Universidade de São Paulo, 1983.

FAORO, Raymundo. Os Donos do Poder: Formação do Patronato Político no Brasil.

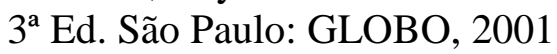


FONTANA, Felipe. A Presença de Durkheim em Oliveira Vianna: Contribuições ao Pensamento Social e Político Brasileiro. Dissertação de Mestrado do Programa de PósGraduação em Ciências Sociais da Universidade Estadual de Maringá (PGC-UEM), 2013.

FONTANA, Felipe; FEREZIN, Carla Cristina Wrbieta. Os limites da democracia no Brasil: A leitura de Oliveira Vianna sobre a formação do Brasil revista pelas problematizações de Adrián Gurza Lavalle acerca da esfera e da vida pública brasileira. Revista Agenda Política, UFSCar, 2013, vol. 01, n. 02, p. 72-96. Disponível em: 〈http://www.agendapolitica.ufscar.br/index.php/agendapolitica/article/view/19>. Acesso em: 15 jul.2014.

Oliveira Vianna, Azevedo Amaral e Virginio Santa Rosa: Expoentes de um Pensamento Autoritário no Brasil? In: IX ABCP: Brasília, 2014. Disponível em: < http://www.encontroabcp2014.cienciapolitica.org.br/resources/anais/14/1403741872_A RQUIVO_ArtigoParaIXABCP-2014-FelipeFontana\&CarlaFerezin-VersaoFinal.pdf>. Acesso em: 15 dez. 2014.

O Diagnóstico sobre o Brasil: Oliveira Vianna e sua Primeira Grande Contribuição à Ciência Política Brasileira. Revista Florestan, no 1, v. 1, 2014, p. 116125. Disponível em: 〈www.revistaflorestan.ufscar.br> . Acesso em: 15 jul. 2014.

HOLANDA, Sérgio Buarque. Raízes da Brasil. 26ªd. São Paulo: Companhia das Letras e Editora SCHWARCZ LTDA, 2006.

HURTING, Serge. Introdução à Sociologia Política. Análise Social, Volume IV, 1966 (N. $\left.{ }^{\circ} 13\right), 5-164$. Disponível em:

<http://analisesocial.ics.ul.pt/documentos/1224166005W9wXA0xp2Ux23DU8.pdf>. Acesso em: 21 out. 2014.

JANOSKI, Thomas; HICKS, Alexander; SCHWARTZ, Mildred A. Introduction: Political Sociology in the new Millennium. In: The Handbook of Political Sociology: States, Civil Societies, and Globalization. JANOSKI, Thomas; ALFORD, Robert; HICKS, Alexander; SCHWARTZ, Mildred A. (Orgs.). New York: Cambridge University Press, 2005, p. 01-29. Disponível em: <http://obinfonet.ro/docs/apocal/apocarex/handbook-of-political-sociology.pdf $>$. Acesso em: 15 ago. 2015.

NABUCO, Joaquim. Porque Continuo a ser Monarchista. (Carta ao Diário do Commercio, 1890). Arquivo Fundação Joaquim Nabuco. Disponível em: < http://www.dominiopublico.gov.br/pesquisa/DetalheObraForm.do? select_action=\&co obra=15688>. Acesso em: 22 jul. 2013. 
PERISSINOTTO, Renato. Política e sociedade: por uma volta à Sociologia Política. Revista Sociologia e Política, UFSC, v.3, n. 5, 2004, p. 118-138. Disponível em: $<$ https://periodicos.ufsc.br/index.php/politica/article/viewFile/1986/1735>. Acesso em: 14 ago. 2015.

REIS, Elisa Pereira. Sociologia Política e processos macro-históricos. Sociologias. Porto Alegre, 2015, vol. 17, n. 38, p. 18-43. Disponível em: < http://www.scielo.br/pdf/soc/v17n38/1517-4522-soc-17-38-00018.pdf>. Acesso em: 12 ago. 2015.

RICHARD, Gaston. Sociologie Générale: Et Les Lois Sociologiques. Paris: Octave Doin Et Fils, Éditeur, 1912. Disponível em: Acervo do Museu Casa de Oliveira Vianna. Acesso em: 14/07/2011.

SCHWARZ, Roberto. As Ideias Fora de Lugar. In Ao Vencedor as Batatas. São Paulo: Duas cidades; 34 Letras, 2000.

SILVA, Ricardo. Liberalismo e democracia na Sociologia Política de Oliveira Vianna. Sociologias. Porto Alegre, 2008, vol. 10, n. 20, p. 238-269. Disponível em: < http://www.scielo.br/pdf/soc/n20/a11n20.pdf >. Acesso em: 10 ago. 2015.

TÔRRES, Vasconcelos. Oliveira Vianna - sua Vida e sua Posição nos Estudos Brasileiros de Sociologia. Rio de Janeiro: Livraria Freitas Bastos S.A, 1956.

VIANNA, Oliveira. Instituições Políticas Brasileiras (Primeiro e Segundo Volume). Brasília: Conselho Editorial do Senado Federal, 1999. Disponível em:

<http://www.senado.gov.br/web/conselho/conselho.htm>. Acesso em: 20 set. 2010.

Populações Meridionais do Brasil: Populações Rurais do Centro Sul (Paulistas-Fluminenses-Mineiros). 4ªed. São Paulo: Companhia Editora Nacional, 1938. (Volume I).

Populações Meridionais do Brasil: Populações Rurais do Centro Sul (Paulistas-Fluminenses-Mineiros). Brasília: Conselho Editorial do Senado Federal, 2005. Disponível em: <http://www.senado.gov.br/web/conselho/conselho.htm>. Acesso em: 20 set. 2010.

Populações Meridionais do Brasil: Populações Rurais do Centro Sul (Paulistas-Fluminenses-Mineiros). $7^{\mathrm{a}}$ ed. Niterói: Editora da Universidade Federal Fluminense, 1987. (Volume I). 
Problemas de Organização e Problemas de Direção: o Povo e o Governo. $2^{\mathrm{a}}$ Ed. Rio de Janeiro - São Paulo: Record Cultural, 1974.

O Idealismo da Constituição. In: CARDOSO, Vicente Licínio (Org.). À Margem da História da República. $1^{\text {a }}$ Ed. Brasília: Editora Universidade de Brasília, 1981, p. 103-118.

O Idealismo da Constituição. Rio de Janeiro: Edição de Terra do Sol, 1927. VIEIRA, Evaldo. Autoritarismo e Corporativismo no Brasil: Oliveira Vianna \& Companhia. $2^{\mathrm{a}}$ ed. São Paulo: Cortez, 1981. 